\title{
Comparison of dobutamine and dopamine in treatment of severe heart failure ${ }^{1}$
}

\author{
JOHN D. STONER III, JAMES L. BOLEN, ${ }^{2}$ AND DONALD C. HARRISON \\ From the Division of Cardiology, Stanford University School of Medicine, Stanford, California 94305, \\ U.S.A.
}

The haemodynamic effects of dobutamine, a new synthetic catecholamine, were studied in 12 patients with severe congestive heart failure and compared with those of dopamine in 10 clinically similar patients. Dobutamine produced a distinct increase in cardiac index, while lowering left ventricular end-diastolic pressure and leaving mean aortic pressure unchanged. Dopamine also significantly improved cardiac index, but at the expense of a greater increase in heart rate than occurred with dobutamine. Dopamine was ineffective in lowering left ventricular end-diastolic pressure, but increased mean aortic pressure. We conclude that dobutamine is an effective, positive inotropic agent in patients with severe congestive heart failure. Because it has comparatively little effect on heart rate and aortic pressure, both major determinants of myocardial oxygen consumption, it may be of special value in patients with the low output syndrome associated with coronary heart disease.

The treatment of severe congestive heart failure continues to be a challenging problem in spite of many new and innovative pharmacological, mechani$\mathrm{cal}$, and surgical approaches. The sympathomimetic amines remain one of the primary forms of therapy because of their potent inotropic effect, yet none of those currently available for clinical use is wholly satisfactory. Noradrenaline produces excessive systemic vasoconstriction, decreasing tissue perfusion while increasing arterial pressure and cardiac work (Cohn and Luria, 1965; Vatner et al., 1974a). Isoprenaline may increase heart rate and predispose to potentially fatal arrhythmias (Innes and Nickerson, 1975; Smith et al., 1967). Peripherally, it induces beta-adrenergic vasodilatation, diverting cardiac output to noncritical tissues while lowering arterial and coronary perfusion pressure (Elliott and Gorlin, 1966; Gunnar et al., 1967). In patients with coronary artery disease it may worsen myocardial ischaemia and increase infarct size (Maroko et al., 1971; Lipp et al., 1972). Dopamine is associated with considerably less chronotropic effect, but still may produce ventricular arrhythmias (Lipp et al., 1972; Gunnar and Loeb, 1972). Though it lowers renal vascular resistance through stimulation of

\footnotetext{
${ }^{1}$ This work was supported in part by NIH Grants.

'Present address: Evans Central Cardiology Group, 500 East Colonial Drive, Orlando, Florida 32803, U.S.A.

Received for publication 29 June 1976
}

specific dopamine receptors, it has a predominantly alpha-adrenergic action on other arterial beds and may produce excessive vasoconstriction in high doses (McNay et al., 1965; Goldberg, 1972; Vatner et al., 1973). More importantly, dopamine's inotropic effect is mediated in part through the release of endogenous noradrenaline (Tsai et al., 1967; Nash.et al., 1968). In severe heart failure, when endogenous noradrenaline stores are low, its ability to improve cardiac output may be reduced and unpredictable (Chidsey et al., 1963; Tuttle and Mills, 1975).

Dobutamine ([ \pm$]-4-[2-[[3-(p-h y d r o x y p h e n y l)-1-$ methyl propyl] amino] ethyl] pyrocatechol hydrochloride) is a new synthetic sympathomimetic amine developed in an effort to reduce the deleterious effects associated with currently available inotropic agents (Tuttle and Mills, 1975). Though a derivative of dopamine, it acts directly on adrenergic receptors rather than through release of endogenous noradrenaline. Preliminary studies indicate that it dramatically improves cardiac output with relatively little chronotropic or peripheral vascular effect (Gunnar et al., 1973; Vatner et al., 1974b; Robie et al., 1974; Akhtar et al., 1975). It remains to be established, however, whether dobutamine is clinically a more effective therapeutic agent. Accordingly, this study was undertaken to assess the degree of haemodynamic improvement produced by dobutamine in patients with severe heart failure and 
to compare its effects with those of dopamine in a similar group of patients.

\section{Methods}

Twelve patients undergoing routine diagnostic cardiac catheterisation were studied. All had evidence of severe left ventricular dysfunction, either on the basis of coronary artery disease or cardiomyopathy. None had significant valvular abnormalities.

At the end of the diagnostic cardiac catheterisation, control haemodynamic measurements were made, including right atrial, pulmonary artery, pulmonary capillary wedge, left ventricular, and aortic pressures. Cardiac output was measured using the Fick method. Arterial and mixed venous oxygen content were determined using an Instrumentation Laboratory spectrophotometer. From these, systemic and pulmonary vascular resistances were calculated. Maximal left ventricular dp/dt was obtained by computer analysis of the left ventricular pressure tracing. Left ventricular pressures were recorded through fluid-filled catheters which had been tuned and optimised to provide linear frequency responses up to $16 \mathrm{~Hz}$. These frequency responses have been shown to provide data necessary to obtain high quality left ventricular $\mathrm{dp} / \mathrm{dt}$ measurements. After recording control values, dobutamine was infused intravenously at a rate of $10 \mu \mathrm{g} / \mathrm{kg}$ per min for 15 minutes and the above measurements were repeated.

Haemodynamic data from 10 different patients with similar haemodynamic derangements previously studied in our laboratory during dopamine administration are presented for comparison (Holloway et al., 1975). All had severe left ventri-

Table 1 Haemodynamics in 12 patients with severe left ventricular failure before and after dobutamine infusion $($ mean $\pm S E M)$

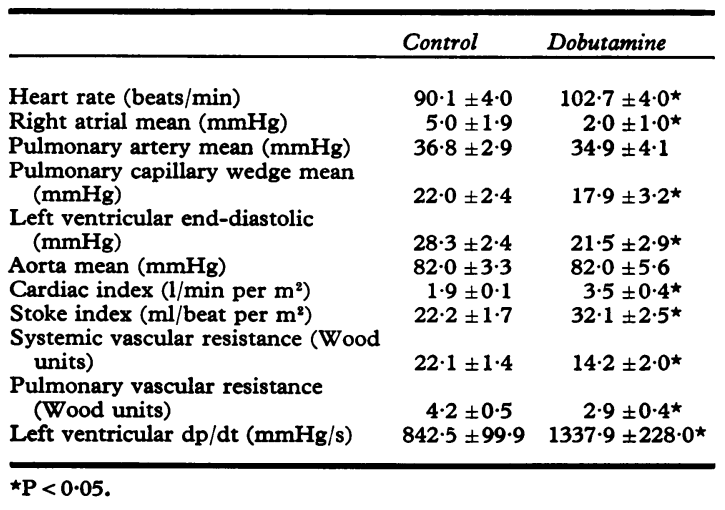

cular dysfunction without evidence of significant valvular abnormalities. Control haemodynamic measurements were made as described above. An infusion of dopamine $(100 \mu \mathrm{g} / \mathrm{ml})$ was begun at a rate of $2 \mu \mathrm{g} / \mathrm{kg}$ per min for 5 minutes, then increased by $2 \mu \mathrm{g} / \mathrm{kg}$ per min every 5 minutes until mean aortic pressure increased by $15 \mathrm{mmHg}$ or heart rate by 30 beats/min. When either of these limits was reached, the infusion rate was kept constant for an additional 5 minutes and the haemodynamic measurements were repeated. The rate required to obtain the desired end-point ranged from 2 to $16 \mu \mathrm{g} / \mathrm{kg}$ per $\mathrm{min}$.

All statistical analyses were performed using Student's t-test for paired samples, or for unpaired samples with equal variance, and a $P$ value of less than 0.05 was taken as indicative of statistical significance.

\section{Results}

The haemodynamic response to dobutamine infusion in 12 patients with severe left ventricular dysfunction is summarised in Table 1 . The cardiac index increased dramatically from 1.9 to 3.5 $1 / \mathrm{min}$ per $\mathrm{m}^{2}$, largely because of an increase in stroke index $(P<0.001)$. This was accompanied by a fall in left ventricular end-diastolic pressure from 28.3 to $21.5 \mathrm{~mm}(P<0.001)$ and a nearly 60 per cent rise in left ventricular dp/dt $(P<0.005)$. Mean aortic pressure remained constant, while calculated systemic vascular resistance fell by 36 per cent. Mean pulmonary artery pressure was unchanged, while pulmonary vascular resistance was reduced by 31 per cent. Heart rate was increased by a mean of 13 beats $/ \mathrm{min}$.

The haemodynamic response to dopamine infusion in 10 similar patients with left ventricular dysfunction is summarised in Table 2. These results form part of an earlier report (Holloway

Table 2 Haemodynamics in 10 patients with severe left ventricular failure before and after dopamine infusion (mean $\pm S E M)$

\begin{tabular}{|c|c|c|}
\hline & Control & Dopamine \\
\hline $\begin{array}{l}\text { Heart rate (beats/min) } \\
\text { Right atrial mean (mmHg) } \\
\text { Pulmonary artery mean (mmHg) } \\
\text { Pulmonary capillary wedge mean }\left(\mathrm{mmHg}^{\mathrm{m}}\right) \\
\text { Left ventricular end-diastolic ((mmHg) } \\
\text { Aorta mean (mmHg) } \\
\text { Cardiac index }\left(1 / \mathrm{min} \text { per } \mathrm{m}^{2}\right) \\
\left.\text { Stroke index (ml/beat per } \mathrm{m}^{2}\right) \\
\text { Systemic vascular resistance (Wood units) } \\
\text { Pulmonary vascular resistance (Wood } \\
\text { units) }\end{array}$ & $\begin{aligned} 82 \cdot 1 & \pm 4 \cdot 1 \\
6 \cdot 3 & \pm 1 \cdot 2 \\
38 \cdot 2 & \pm 2 \cdot 3 \\
24 \cdot 4 & \pm 1 \cdot 3 \\
28 \cdot 8 & \pm 1 \cdot 4 \\
85 \cdot 4 & \pm 3 \cdot 1 \\
2 \cdot 0 & \pm 0 \cdot 2 \\
24 \cdot 4 & \pm 1 \cdot 9 \\
24 \cdot 0 & \pm 2 \cdot 2 \\
4 \cdot 5 & \pm 0 \cdot 9\end{aligned}$ & $\begin{aligned} 110 \cdot 9 & \pm 5 \cdot 9 \star \\
7 \cdot 9 & \pm 1 \cdot 5 \\
48 \cdot 5 & \pm 4 \cdot 2^{\star} \\
28 \cdot 4 & \pm 2 \cdot 6 \\
30 \cdot 4 & \pm 2 \cdot 9 \\
98 \cdot 4 & \pm 4 \cdot 6^{\star} \\
3 \cdot 0 & \pm 0 \cdot 3^{\star} \\
27 \cdot 0 & \pm 2 \cdot 4 \\
17 \cdot 4 & \pm 1 \cdot 7^{\star} \\
4 \cdot 3 & \pm 0 \cdot 8\end{aligned}$ \\
\hline
\end{tabular}

$\star \mathrm{P}<0.05$. 
et al., 1975). Control cardiac index, left ventricular end-diastolic pressure, mean aortic and pulmonary arterial pressures, systemic vascular resistance, pulmonary vascular resistance, and heart rate are similar to those of the 12 patients receiving dobutamine. Cardiac index increased significantly after dopamine administration, though to a lesser degree than with dobutamine. Left ventricular enddiastolic pressure was unchanged, while mean aortic and pulmonary arterial pressures increased. Heart rate rose by a mean of 29 beats/min, significantly greater than with dobutamine $(P<0.05)$. while stroke index increased by only 11 per cent.

\section{Discussion}

Previous work has shown dobutamine to be a potent and relatively selective inotropic agent with only minor chronotropic and peripheral vascular effect (Vatner et al., 1974b; Robie et al., 1974; Akhtar et al., 1975; Gunnar et al., 1973; Tuttle and Mills, 1975). This study extends these findings to a group of patients with severe heart failure resulting from coronary artery disease or cardiomyopathy, in whom dobutamine might be clinically indicated. When infused at a rate of $10 \mu \mathrm{g} / \mathrm{kg}$ per min, dobutamine dramatically improved left ventricular function, increasing left ventricular $\mathrm{dp} / \mathrm{dt}$ by over 50 per cent, nearly doubling cardiac index, and lowering left ventricular end-diastolic pressure. Dobutamine reduced peripheral vascular resistance and some of its effect could be attributed to this reduction in afterload. The increase in cardiac output and the drop in left ventricular end-diastolic pressure would be influenced by this peripheral vasodilatation. In contrast, the administration of dopamine failed to reduce left ventricular end-diastolic pressure. This lack of reduction of left ventricular end-diastolic pressure could be attributed to the observation that there was an increase in arterial pressure or afterload, since by other measures dopamine clearly produced an inotropic effect. Heart rate rose by 14 per cent, while a nearly 50 per cent increase in stroke index accounted for the majority of the improvement in cardiac output. Mean systemic arterial pressure remained unchanged because of a 36 per cent decline in systemic vascular resistance, the latter reflecting either a reflex reduction in sympathetic tone or a direct effect of dobutamine on the peripheral vasculature.

Comparison of these findings with the haemodynamic effects of dopamine in a similar group of patients, previously studied in our laboratory, reveals several important differences. Dopamine, while administered in doses that significantly increased cardiac index, was ineffective in lowering left ventricular end-diastolic pressure from levels commonly associated with pulmonary oedema. As a result its use may be associated with continued pulmonary vascular congestion and arterial desaturation (Loeb et al., 1975).

Although both drugs produced similar increases in cardiac index with the doses employed, dopamine accomplished this at the expense of a significantly greater increase in heart rate. Systemic arterial pressure also rose with dopamine administration, in spite of a slight decrease in systemic vascular resistance. Since both heart rate and arterial pressure are important determinants of myocardial oxygen consumption (Sonnenblick and Skelton, 1971), these findings suggest that dobutamine may be preferable in treating patients with coronary artery disease. Animal studies using epicardial ST segment mapping and coronary sinus lactate determinations have shown that dopamine may worsen myocardial ischaemia and injury after coronary occlusion (Stemple et al., 1976). In contrast, when dobutamine was administered to patients in clinical heart failure with evolving myocardial infarctions, there was no detectable increase in myocardial injury as determined by hourly serum-CK determinations and a plot of the CK-kinetic curves (Gillespie et al., 1975).

Similarly, dobutamine's pharmacological actions offer distinct advantages over the other currently available inotropic agents. In equivalent doses it induces far less tachycardia than isoprenaline and is not associated with excessive vasodilatation or hypotension (Tuttle and Mills, 1975; Vatner et al., 1974b; Robie et al., 1974). At the other end of the spectrum, the pronounced vasoconstriction that occurs with noradrenaline is also avoided. Instead, dobutamine acts more selectively to improve myocardial contractility and left ventricular function, with tissue perfusion increasing in proportion to cardiac output.

While it is difficult to extrapolate directly to patients treated in the hospital with low cardiac output resulting from cardiomyopathy, we believe that our studies clearly show the effectiveness of dobutamine. Because of its predictable inotropic effects while producing little in the way of increased myocardial oxygen demands, we believe it deserves use in patients with the low output syndrome associated with coronary heart disease.

\section{References}

Akhtar, N., Mikulic, E., Cohn, J. N., and Chaudhry, M. H. (1975). Hemodynamic effect of dobutamine in patients with severe heart failure. American fournal of Cardiology, 36, 202-205.

Chidsey, C. A., Braunwald, E., Morrow, A. G., and Mason, 
D. T. (1963). Myocardial norepinephrine concentration in man: effects of reserpine and of congestive heart failure. New England fournal of Medicine, 269, 653-658.

Cohn, J. N., and Luria, M. H. (1965). Studies in clinical shock and hypotension. II: Hemodynamic effects of norepinephrine and angiotensin. Fournal of Clinical Investigation, 44, 1494-1504.

Elliott, W. C., and Gorlin, R. (1966). Isoproterenol in treatment of heart disease, hemodynamic effects in circulatory failure. Fournal of the American Medical Association, 197, 315-320.

Gillespie, T. A., Roberts, R., Ambos, H. D., and Sobel, B. E. (1975). Salutory effects of dobutamine on hemodynamics without exacerbation of arrhythmia or myocardial injury. Circulation, 52, Suppl. II, II-76.

Goldberg, L. I. (1972). Cardiovascular and renal actions of dopamine: potential clinical applications. Pharmacological Reviews, 24, 1-29.

Gunnar, R. M., and Loeb, H. S. (1972). Use of drugs in cardiogenic shock due to acute myocardial infarction. Circulation, 45, 1111-1124.

Gunnar, R. M., Loeb, H. S., Klodnycky, M., Sinno, M. Z., and Towne, $W$. (1973). Hemodynamic effects of dobutamine in man. Circulation, 47-48, Suppl. IV, IV-132.

Gunnar, R. M., Loeb, H. S., Pietras, R. J., and Tobin, J. R. (1967). Ineffectiveness of isoproterenol in shock due to acute myocardial infarction. Fournal of the American Medical Association, 202, 1124-1128.

Holloway, E. L., Polumbo, R. A., and Harrison, D. C. (1975). Acute circulatory effects of dopamine in patients with pulmonary hypertension. British Heart fournal, 37, $482-485$.

Innes, I. R., and Nickerson, M. (1975). Isoproterenol toxicity and side effects. In The Pharmacological Basis of Therapeutics, 5th ed., p. 494. Ed. by L. S. Goodman and A. Gilman. MacMillan, New York.

Lipp, H., Fallicov, R. E., Resnekov, L., and King, S. (1972). The effects of dopamine on depressed myocardial function following coronary embolization in the closed chest dog. American Heart fournal, 84, 208-214.

Loeb, H., Bredakis, J., and Gunnar, R. (1975). Superiority of dobutamine over dopamine for augmentation of cardiac output in patients with cardiac failure. Circulation, 52, Suppl. II, II-76.

McNay, J. L., McDonald, R. H., Jr., and Goldberg, L. I. (1965). Direct renal vasodilatation produced by dopamine in the dog. Circulation Research, 16, 510-517.
Maroko, P. R., Kjekshus, J. K., Sobel, B. E., Watanabe, T., Covell, J. W., Ross, J., Jr., and Braunwald, E. (1971). Factors influencing infarct size following experimental coronary artery occlusions. Circulation, 43, 67-82.

Nash, C. W., Wolff, S. A., and Ferguson, B. A. (1968). Release of tritiated noradrenaline from perfused rat hearts by sympathomimetic amines. Canadian fournal of Physiology and Pharmacology, 46, 35-42.

Robie, N. W., Nutter, D. O., Moody, C., and McNay, J. L. (1974). In vivo analysis of adrenertic receptor activity of dobutamine. Circulation Research, 34, 663-671.

Smith, J. H., Oriol, A., Morch, J., and McGregor, M. (1967). Hemodynamic studies in cardiogenic shock. Treatment with isoproterenol and metaraminol. Circulation, 35, 1084-1091.

Sonnenblick, E. H., and Skelton, C. L. (1971). Myocardial energetics: basic principles and clinical implications. New England fournal of Medicine, 285, 668-675.

Stemple, D., Griffin, J. C., Kernoff, R. S., and Harrison, D. C. (1976). Metabolic and electrophysiologic effects of nitroprusside and dopamine in experimental acute myocardial infarction. Clinical Research, 24, 141A.

Tsai, T. H., Langer, S. Z., and Trendelenburg, V. (1967). Effects of dopamine and $\alpha$ methyl-dopamine on smooth muscle and on the cardiac pacemaker. Fournal of Pharmacology and Experimental Therapeutics, 156, 310-324.

Tuttle, R. R., and Mills, J. (1975). Dobutamine. Development of a new catecholamine to selectively increase cardiac contractility. Circulation Research, 36, 185-196.

Vatner, S. F., Higgins, C. B., and Braunwald, E. (1974a). Effects of norepinephrine on coronary circulation and left ventricular dynamics in the conscious dog. Circulation Research, 34, 812-823.

Vatner, S. F., McRitchie, R. J., and Braunwald, E. (1974b), Effects of dobutamine on left ventricular performance, coronary dynamics, and distribution of cardiac output in conscious dogs. Fournal of Clinical Investigation, 53, 1265-1273.

Vatner, S. F., Millard, R. W., and Higgins, C. B. (1973). Coronary and myocardial effects of dopamine in the conscious dog: parasympatholytic augmentation of pressor and inotropic actions. Fournal of Pharmacology and Experimental Therapeutics, 187, 280-295.

Requests for reprints to Dr. Donald C. Harrison, Cardiology Division, Stanford University School of Medicine, Stanford, California 94305, U.S.A. 